\title{
Kidins220/ARMS as a functional mediator of multiple receptor signalling pathways
}

\author{
Veronika E. Neubrand ${ }^{1, \star}$, Fabrizia Cesca ${ }^{2, \star}$, Fabio Benfenati ${ }^{2}$ and Giampietro Schiavo ${ }^{3, \pm}$ \\ ${ }^{1}$ Instituto de Parasitología y Biomedicina López-Neyra, IPBLN-CSIC, Avda. Conocimiento S/N, 18100 Armilla, Granada, Spain \\ ${ }^{2}$ Department of Neuroscience and Brain Technologies, Istituto Italiano di Tecnologia, via Morego 30, 16163 Genova, Italy \\ ${ }^{3}$ Molecular Neuropathology Laboratory Cancer Research UK London Research Institute, 44 Lincoln's Inn Fields, London, WC2A 3LY, UK \\ *These authors contributed equally to this work \\ ${ }^{\ddagger}$ Author for correspondence (giampietro.schiavo @ cancer.org.uk) \\ Journal of Cell Science 125, 1845-1854 \\ (C) 2012. Published by The Company of Biologists Ltd \\ doi: $10.1242 / j c s .102764$
}

\section{Summary}

An increasing body of evidence suggests that several membrane receptors - in addition to activating distinct signalling cascades - also engage in substantial crosstalk with each other, thereby adjusting their signalling outcome as a function of specific input information. However, little is known about the molecular mechanisms that control their coordination and integration of downstream signalling. A protein that is likely to have a role in this process is kinase-D-interacting substrate of $220 \mathrm{kDa}$ [Kidins220, also known as ankyrin repeatrich membrane spanning (ARMS), hereafter referred to as Kidins220/ARMS]. Kidins220/ARMS is a conserved membrane protein that is preferentially expressed in the nervous system and interacts with the microtubule and actin cytoskeleton. It interacts with neurotrophin, ephrin, vascular endothelial growth factor (VEGF) and glutamate receptors, and is a common downstream target of several trophic stimuli. Kidins220/ARMS is required for neuronal differentiation and survival, and its expression levels modulate synaptic plasticity. Kidins220/ARMS knockout mice show developmental defects mainly in the nervous and cardiovascular systems, suggesting a crucial role for this protein in modulating the cross talk between different signalling pathways. In this Commentary, we summarise existing knowledge regarding the physiological functions of Kidins220/ARMS, and highlight some interesting directions for future studies on the role of this protein in health and disease.

Key words: Kidins220/ARMS, Neuronal differentiation, Neurotrophins, RTK signalling, Synaptic plasticity

\section{Introduction}

The correct development of the nervous system relies on the ability of axons and dendrites to recognise their targets. During this highly regulated process, neurons migrate and form functional connections in response to gradients of growth factors that regulate multiple neuronal functions, including cell survival, differentiation and synaptic plasticity (Bibel and Barde, 2000; Chao, 2003; Huang and Reichardt, 2003). The neurotrophin (NT) family is one of the best-characterised groups of neurotrophic factors and includes nerve growth factor (NGF), brain derived neurotrophic factor (BDNF), and neurotrophin-3 (NT3) and -4 (NT4, also known as NT4/5) (Huang and Reichardt, 2001). Neurotrophins bind with high affinity to three related tropomyosin receptor kinases (Trks): NGF binds mainly to TrkA, whereas BDNF and NT4/5 bind mainly to TrkB, and NT3 to TrkC. In addition, all neurotrophins also bind to the p75 neurotrophin receptor ( $75^{\mathrm{NTR}}$, also known as NGFR), a member of the tumour necrosis factor (TNF)-receptor superfamily (Bibel and Barde, 2000). Other growth factors that are paramount in neuronal growth and development are the glial-cell-line-derived neurotrophic factor (GDNF), which acts through the Ret tyrosine kinase receptor, and the GDNF family receptor $\alpha(\mathrm{GFR} \alpha)$ (Paratcha and Ledda, 2008). In addition, trophic factors such as the VEGF and the ephrin-ephrin-receptor (ephrin-Eph) families have crucial roles both inside and outside the nervous system (Klein, 2009; Ruiz de Almodovar et al., 2009).
The vast majority of these ligands perform their physiological functions through plasma membrane receptors that have tyrosine kinase activity - the receptor tyrosine kinases (RTKs) - which results in distinct signalling outputs and cellular effects. However, how RTKs mediate such diverse biological outcomes by starting from a common subset of signalling molecules - such as the Ras protein family, the extracellular regulated kinases (ERKs; also known as mitogen activated protein kinases, MAPKs), Akt and phospholipase C $\gamma$ (PLC $\gamma)-$ is presently unclear. The signal specificity of NT receptors is tuned by a number of factors, including the repertoire of Trk receptors and the level of $\mathrm{p} 75^{\mathrm{NTR}}$ expressed by a particular neuron, which determine the subset of neurotrophins to which a particular neuron would respond (Clary and Reichardt, 1994; Strohmaier et al., 1996; Hapner et al., 1998; Palko et al., 1999; Stoilov et al., 2002). Upon binding of NTs, Trk receptors dimerise and cross-phosphorylate each other. Activated Trk receptors are then able to recruit a number of adaptors through their phosphorylated residues. At the intracellular level, availability of different substrates or adaptors could, thus, control signalling downstream of Trk receptors (Lee et al., 2001). Additionally, the response to neurotrophin signals depends on the temporal and spatial pattern of stimulation. Thus, transient or sustained activation of the MAPK, phosphoinositide kinase-3 (PI3K) or Akt pathways mediates distinct cellular effects, for example by promoting a local and fast response at the growth cone compared with a slower response at distal sites, such as the 
soma (Marshall, 1995; Kuruvilla et al., 2000; Watson et al., 2001). To add a further level of complexity, different receptors can interact with each other. For example, p $75^{\mathrm{NTR}}$ is found in complex with Trk, sortilin-1 (Sorl1) or Nogo (RTN4R) receptors (Bronfman and Fainzilber, 2004), whereas TrkB interacts with ephrin-A7 and EphA5 (Fitzgerald et al., 2008; Marler et al., 2008). Similarly, GDNF $\alpha$, Ret tyrosine kinase and protocadherins cooperate to regulate neuronal survival (Schalm et al., 2010), and the interaction between EphB and N-methyl-D-aspartate (NMDA) receptors - an important class of glutamate receptors - is crucial for the modulation of synaptic plasticity (Dalva et al., 2000; Henderson et al., 2001). Thus, a complex interplay between the repertoire of receptors and the availability of downstream effectors ultimately determines the response of a neuron to a given stimulus.

A common downstream effector of these pathways is the scaffolding protein Kidins220/ARMS. In mice, embryos that lack Kidins220/ARMS die at birth, indicating that this protein is essential for life. In addition to a variety of neuronal phenotypes, these embryos show severe defects in vascular development and cardiac malformations, which are likely to be the cause of death (Cesca et al., 2011; Cesca et al., 2012). Mutants of Kidins220/ ARMS have been described in Caenorhabditis elegans (tag-114) and Drosophila melanogaster (Dmel $\backslash$ CG42672) (see also http:// www.wormbase.org/ and http://flybase.org/). However, only a partial phenotypic characterisation of these mutants has been provided so far, making the analysis performed in mice the most informative to date.

\section{Kidins220/ARMS is a multifunctional scaffolding protein}

Kidins220/ARMS was initially identified as a substrate for protein kinase D (PKD) in neural cells (Iglesias et al., 2000), and independently characterised as a downstream target of the signalling mediated by neurotrophins and ephrins (Kong et al., 2001). Kidins220/ARMS is an integral membrane protein, containing four transmembrane segments in the central part of the molecule, and $\mathrm{N}$ - and $\mathrm{C}$-terminal tails both exposed to the cytoplasm (Fig. 1). Sequence analysis of Kidins220/ARMS revealed the presence of numerous domains that mediate protein-protein interactions. The N-terminus of Kidins220/ ARMS contains eleven ankyrin repeats (residues 37-398 in the mouse sequence), which form a concave binding surface that is accessible to molecular partners, such as the Rho-guanine nucleotide exchange factor (RhoGEF) Trio (Neubrand et al., 2010). Kidins220/ARMS has been included in the Kidins220/ ARMS and PifA (KAP) family of P-loop nucleotide phosphatases (NTPases). P-loop NTPases contain Walker A and Walker B motifs (WA and WB, respectively) (Higgins et al., 1988), which are often involved in the binding of nucleotides and have been identified in the juxtamembrane regions flanking the $\mathrm{N}$ - and $\mathrm{C}$ terminus of Kidins220/ARMS. Members of this family are predicted to mediate the assembly of protein complexes that are associated with the inner surface of cell membranes (Aravind et al., 2004). Interestingly, Kidins220/ARMS binds ATP (Teresa Iglesias and G.S., unpublished), although a functional role for its Walker motifs has so far not been established. Thus, further work is required to establish whether Kidins220/ARMS

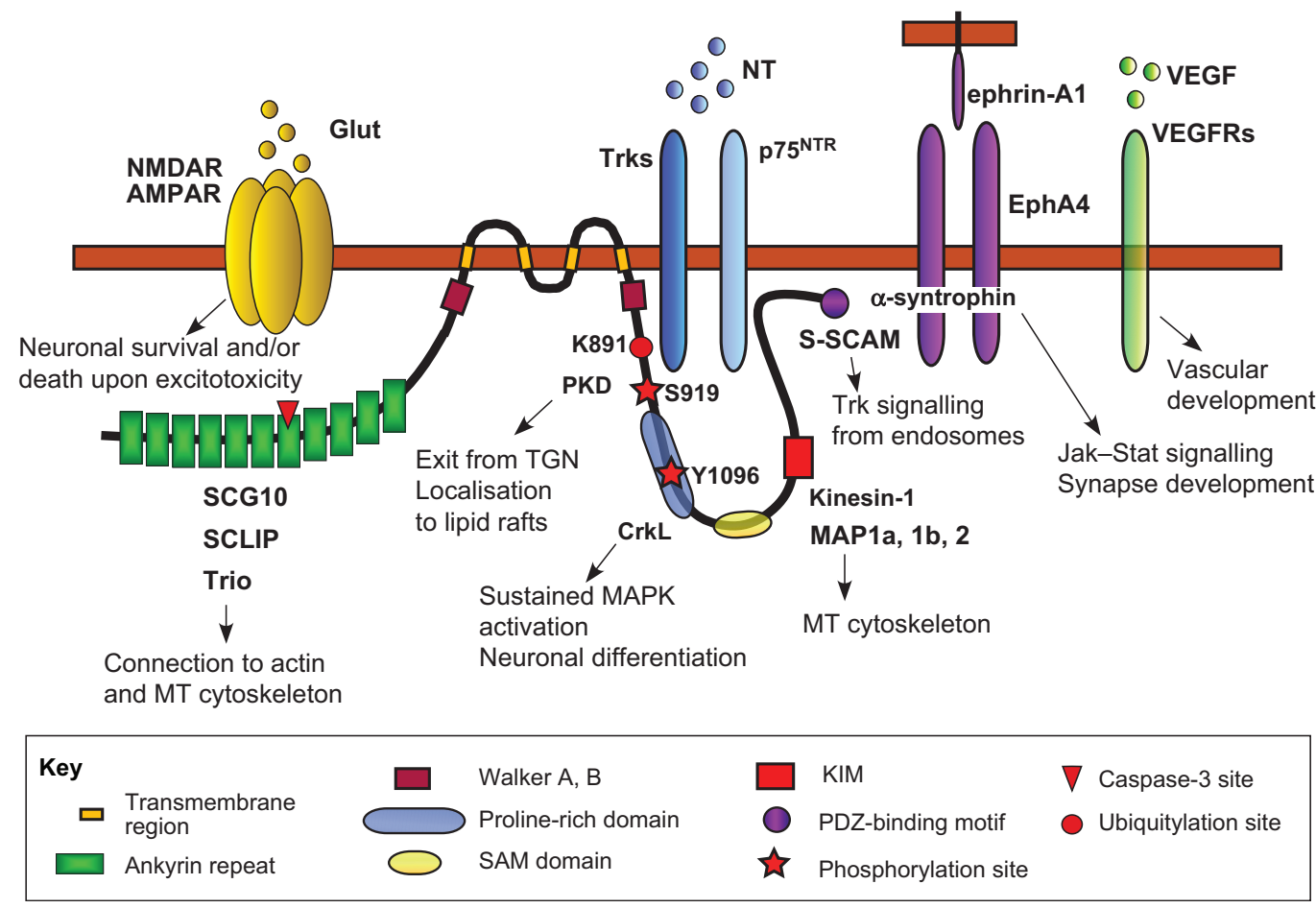

Fig. 1. Kidins220/ARMS engages in multiple protein-protein interactions. Schematic structure of Kidins220/ARMS with its different domains and sites of post-translational modifications. Also shown are the molecular partners identified to date, together with the cellular events that are triggered by their binding to Kidins220/ARMS (arrows). The domains of Kidins220/ARMS mediating the interaction with the various partners are listed in Table 1. AMPAR, AMPA receptor; Glut, glutamate; MT, microtubule; NT, neurotrophins, NMDAR, NMDA receptor. 
has a detectable NTPase activity, or whether ATP binding is required for its function.

The C-terminus of Kidins220/ARMS includes several proteinprotein interaction domains; for example a proline-rich region (residues 1080-1092) that binds the adaptor protein CrkL (Arevalo et al., 2006), and a sterile alpha motif (SAM; residues 1231-1300) (Iglesias et al., 2000; Kong et al., 2001) that might be involved in both inter- and intra-molecular interactions. In addition, the kinesin light chain (KLC)-interacting motif (KIM) (residues 1387-1426) binds the kinesin-1 motor complex (Bracale et al., 2007). The last four amino acids of Kidins220/ ARMS constitute a PDZ-binding motif that binds the PDZ domain of $\alpha$-syntrophin, thereby forming a complex that is associated with the EphA4 receptor at the neuromuscular junction (Luo et al., 2005).

The observation that Kidins220/ARMS interacts with all three Trk receptors and with p $75^{\mathrm{NTR}}$ (Arevalo et al., 2004; Chang et al., 2004) prompted a series of studies on the role of Kidins $220 /$ ARMS in various aspects of neurotrophin physiology, mostly focusing on the molecular mechanisms by which Kidins220/ ARMS mediates Trk signalling (Arevalo et al., 2004; Arevalo et al., 2006). With its multiple domains, Kidins220/ARMS is a well-suited candidate to act as a signalling platform, by recruiting cell-specific adaptors and effectors to activated Trk receptors. Kidins220/ARMS is also involved in functional interactions with several other receptors, such as glutamate, Eph and VEGF receptors (VEGFRs) (Luo et al., 2005; Lopez-Menendez et al., 2009; Arevalo et al., 2010; Cesca et al., 2012), thus representing an example of how different trophic pathways can converge and, possibly, be integrated at the level of a single adaptor molecule. A list of the Kidins220/ARMS interactors identified to date is presented in Table 1.

\section{Kidins220/ARMS in evolution}

Bioinformatic analysis revealed Kidins220/ARMS orthologues in several metazoans (Fig. 2A; Table 2) [(Iglesias et al., 2000; Kong et al., 2001) and (Probir Chakravarty, unpublished)]. In a phylogenetic tree, mammalian, avian and reptilian proteins are clustered together, and have a high degree of sequence similarity (94-80\% among mammals; 94-75\% overall). Frog and fish protein sequences have an intermediate level of similarity
(70-75\% and 61-66\%, respectively) compared with those of mammalian proteins, whereas Kidins220/ARMS amino acid sequences in nematoda, tunicata and cnidaria are considerably different from those in the other groups (Fig. 2A). Another phylogenetic cluster of Kidins220/ARMS homologues is represented by insects, whose protein sequences are more similar to each other than to any other organism. With the exception of the D. melanogaster Kidins220/ARMS sequence (which has an additional N-terminal extension) and that of Bombus terrestris (for which an N-terminal extension is also predicted), the N-terminal region of Kidins220/ARMS is highly conserved, whereas its C-terminal part is more divergent (Fig. 2B). On the basis of this analysis, it is possible that cytoskeletal remodelling, which is the main function associated with the N-terminus (Higuero et al., 2010; Neubrand et al., 2010; Park et al., 2010), is the most 'ancient' function of Kidins220/ ARMS. This role has been maintained through evolution in organisms such as D. melanogaster and C. elegans, for which a canonical neurotrophin pathway has not yet been identified. As Kidins220/ARMS is present in cells of the immune system (RiolBlanco et al., 2004; Ni et al., 2010; Jean-Mairet et al., 2011; Ni et al., 2011) and it is likely to be expressed in the cardiovascular system - hypothesised on the basis of functional data (Cesca et al., 2011; Cesca et al., 2012) - the C- and N-terminal parts of Kidins220/ARMS might have diverged, reflecting the different specialisation of tissues and organs in the various phylogenetic groups. Interestingly, the ephrin-Eph and VEGF-VEGFR pathways are more conserved in evolution than the neurotrophinTrk system, and have also been identified in invertebrates (Drescher, 2002; Shibuya, 2002; Seipel et al., 2004; Mellott and Burke, 2008). Therefore, the neurotrophic function of Kidins220/ ARMS might be a feature in organisms with a more complex nervous system, whereas in lower organisms, Kidins220/ARMS might contribute to the development of other tissues by modulating ephrin-Eph and VEGF-VEGFR pathways.

\section{Kidins220/ARMS and neurotrophin signalling}

As previously mentioned, Kidins220/ARMS interacts with Trk receptors (Arevalo et al., 2004), forming a ternary complex with p $75^{\text {NTR }}$ (Chang et al., 2004). The interaction between Kidins220/ ARMS and TrkA is mediated by the fourth transmembrane

Table 1. Kidins220/ARMS binding partners

\begin{tabular}{|c|c|c|}
\hline Binding partner & Kidins220/ARMS binding site & References \\
\hline AMPAR-GluA1 & Transmembrane domains & (Arevalo et al., 2010) \\
\hline$\alpha$-syntrophin & PDZ-binding motif & (Luo et al., 2005) \\
\hline CrkL & Proline-rich domain & (Arevalo et al., 2006) \\
\hline EphA4 & n.d. & (Luo et al., 2005) \\
\hline Kinesin 1 & KIM motif & (Bracale et al., 2007) \\
\hline MAP1a, MAP1b, MAP2 & Residues 760-1762 & (Higuero et al., 2010) \\
\hline NMDA receptor & n.d. & (Lopez-Menendez et al., 2009) \\
\hline $\mathrm{p} 75^{\mathrm{NTR}}$ & Residues 1512-1762 & (Kong et al., 2001) \\
\hline PDZ-GEF1 & Indirect binding through S-SCAM & (Hisata et al., 2007) \\
\hline PKD & n.d. & (Iglesias et al., 2000) \\
\hline SCG10 & Ankyrin repeats & (Higuero et al., 2010) \\
\hline SCLIP & Ankyrin repeats & (Higuero et al., 2010) \\
\hline Septin 5 & Residues 1603-1715 & (Park et al., 2010) \\
\hline S-SCAM & PDZ-binding motif & (Hisata et al., 2007) \\
\hline Trio, kalirin & Ankyrin repeats & (Neubrand et al., 2010) \\
\hline TrkA, TrkB, TrkC & Transmembrane domain & $\begin{array}{l}\text { (Kong et al., 2001; } \\
\text { (Arevalo et al., 2004) }\end{array}$ \\
\hline VEGFR2, VEGFR3 & n.d. & (Cesca et al., 2012) \\
\hline
\end{tabular}


A

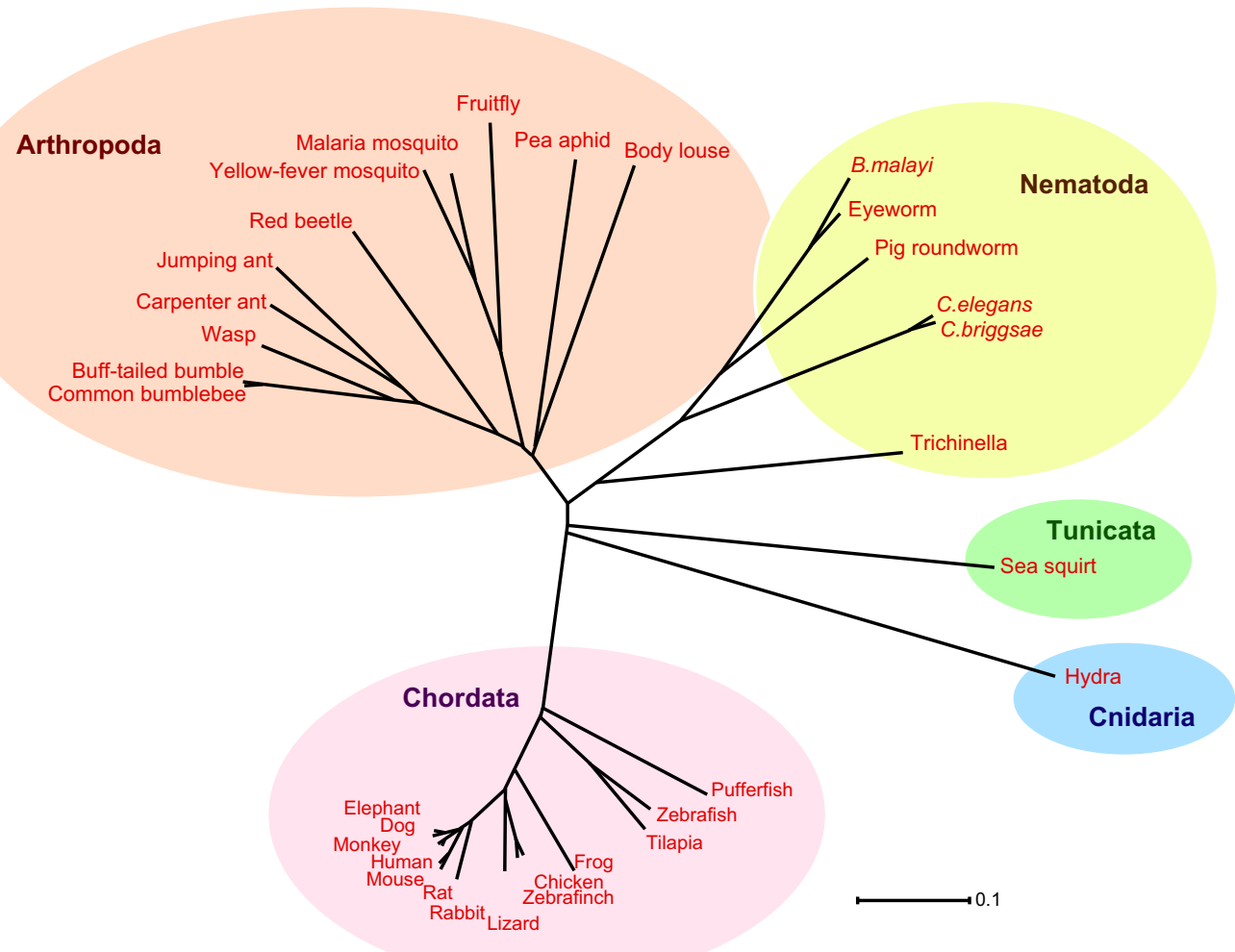

B

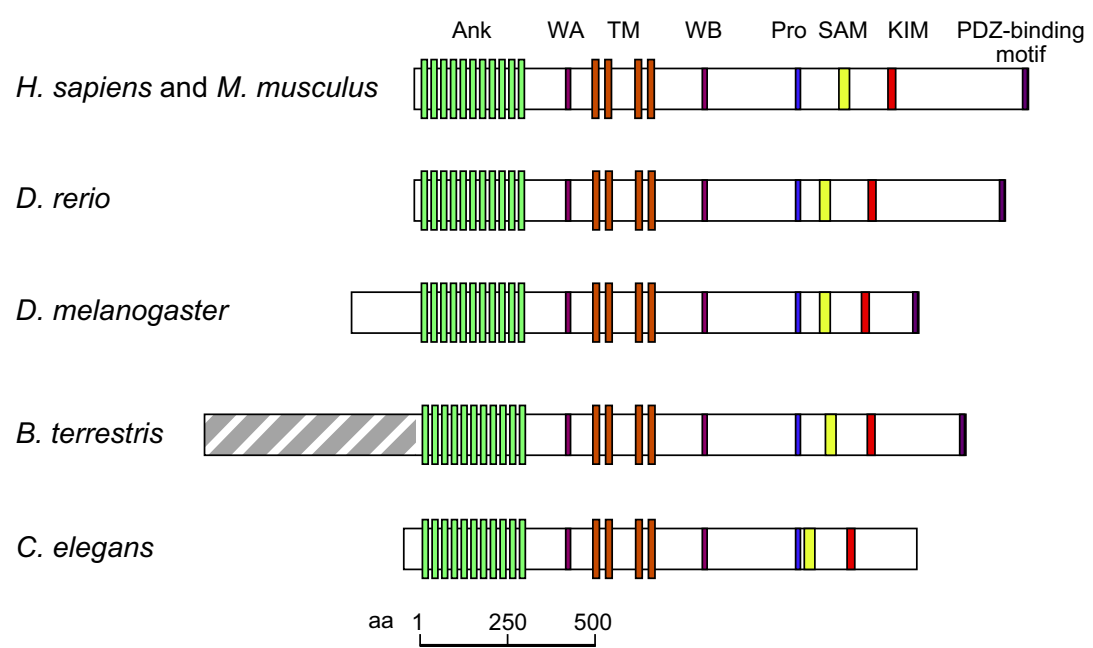

Fig. 2. Kidins220/ARMS in evolution. (A) Dendrogram of Kidins220/ARMS orthologues. The branch lengths are proportional to the amount of inferred evolutionary change between sequences. GenBank accession numbers are listed in Table 2. (B) Schematic of Kidins220/ARMS domain structure in the indicated species. Alternative splicing may occur in the C-terminal region between the KIM motif and the PDZ-binding domain (Iglesias et al., 2000). The shaded grey box in the B. terrestris sequence indicates a predicted N-terminal extension. Ank, ankyrin repeats; WA, Walker A motif; WB, Walker B motif; TM, transmembrane regions; Pro, proline-rich domain.

domain of Kidins220/ARMS and the transmembrane domain of TrkA (Arevalo et al., 2004) (Fig. 1), whereas the interaction with p $75^{\text {NTR }}$ involves the last 250 amino acids of Kidins220/ARMS (Kong et al., 2001) and the p $75^{\mathrm{NTR}}$ intracellular domain (residues 327-342) (Chang et al., 2004). The binding of Trk receptors and $\mathrm{p} 75^{\mathrm{NTR}}$ to Kidins220/ARMS is differentially modulated by neurotrophins. Formation of a Kidins220-TrkA complex is NGF-dependent and persists for up to 25 hours following stimulation with NGF (Kong et al., 2001). The assembly of the ternary complex between Kidins220/ARMS, TrkA and $p 75^{\mathrm{NTR}}$ is however independent of NGF (Chang et al., 2004). Interestingly, increased levels of Kidins220/ARMS reduce the binding of TrkA to $\mathrm{p} 75^{\mathrm{NTR}}$, suggesting that Kidins220/ARMS regulates the formation of receptor complexes that display different neurotrophin-binding affinities (Chang et al., 2004). In addition, Kidins220/ARMS selectively mediates the sustained 
Table 2. Kidins220/ARMS orthologues and their GenBank accession numbers

\begin{tabular}{|c|c|c|}
\hline Organism & Common name & $\begin{array}{c}\text { GenBank accession } \\
\text { number }\end{array}$ \\
\hline Acyrthosiphon pisum & Pea aphid & XP_001943427 \\
\hline Anolis carolinensis & Lizard & XP_003215436 \\
\hline Anopheles gambiae & Malaria mosquito & XP_320386 \\
\hline Ascaris suum & Pig roundworm & ADY40531 \\
\hline Bombus impatiens & Common bumblebee & XP_003493060 \\
\hline Bombus terrestris & Buff-tailed bumble & XP_003400873 \\
\hline Brugia malayi & Round worm & XP_001895979 \\
\hline Caenorhabditis briggsae & Worm & XP_002633264 \\
\hline Caenorhabditis elegans & Worm & CAA 92996 \\
\hline Camponotus floridanus & Carpenter ant & EFN63057 \\
\hline Canis lupus familiaris & Dog & XP_532865 \\
\hline Culex quinquefasciatus & Yellow-fever mosquito & XP_001843847 \\
\hline Danio rerio & Zebrafish & NP_956276 \\
\hline Drosophila melanogaster & Fruitfly & NP_611574 \\
\hline Gallus gallus & Chicken & XP_419939 \\
\hline Harpegnathos saltator & Jumping ant & EFN̄ 89445 \\
\hline Homo sapiens & Human & NP_065789 \\
\hline Hydra magnipapillata & Hydra & XP_002154747 \\
\hline Loa loa & Eye worm & XP_003141375 \\
\hline Loxodonta africana & Elephant & XP_003411847 \\
\hline Macaca mulatta & Monkey & XP_001083478 \\
\hline Mus musculus & Mouse & NP_001074847 \\
\hline Nasonia vitripennis & Wasp & XP_003426415 \\
\hline Oikopleura dioica & Sea squirt & CB̄̄ 24367 \\
\hline Oreochromis niloticus & Tilapia & XP_003446685 \\
\hline Oryctolagus cuniculus & Rabbit & XP_002722525 \\
\hline Pediculus humanus corporis & Body louse & XP_00242719 \\
\hline Rattus norvegicus & Rat & NP_446247 \\
\hline Taeniopygia guttata & Zebra finch & XP_002197621 \\
\hline Tetraodon nigroviridis & Pufferfish & CAG 10502 \\
\hline Tribolium castaneum & Red beetle & XP_001811729 \\
\hline Trichinella spiralis & Pork worm & XP_003380555 \\
\hline Xenopus tropicalis & Frog & NP_001120159 \\
\hline
\end{tabular}

activation of MAPK signalling, without affecting the fast response to neurotrophins or the response to other growth factors, such as epidermal growth factor (EGF) (Kong et al., 2001; Arevalo et al., 2004).

Kidins220/ARMS is phosphorylated on tyrosine residues in response to NGF and BDNF, the time course of which follows the kinetics of Trk autophosphorylation and therefore suggests that this protein is a Trk receptor substrate (Kong et al., 2001). In addition, tyrosine phosphorylation of Kidins220/ARMS occurs simultaneously with that of Shc and PLC $\gamma$, indicating that this protein is amongst the first to be activated in response to NGF (Arevalo et al., 2004). The adaptor protein CrkL constitutively binds the second poly-proline stretch of Kidins220/ARMS through its SH3 domain (Arevalo et al., 2006). Upon treating cells with NGF, Kidins220/ARMS is phosphorylated at tyrosine 1096, causing a conformational change in the CrkL-Kidins220/ ARMS complex. This allows the recruitment of downstream modulators of the MAPK pathway, such as C3G and Rap1 (Arevalo et al., 2006), and determines its sustained activation, which occurs mainly at late endosomes (Hisata et al., 2007). This effect is highly specific, as perturbing Kidins220/ARMS function by using RNA interference (RNAi) or dominant-negative Kidins220/ARMS constructs does not affect the transient MAPK activation triggered by EGF and the initial steps of MAPK signalling, which are Ras- or Akt-dependent (Arevalo et al., 2004). Impairment of BDNF-induced MAPK activation has also been demonstrated in Kidins220/ARMS-deficient neurons (Cesca et al., 2012). Among the transcription factors activated by the MAPK pathway, Kidins220/ARMS promotes nuclear factorkappa B $(\mathrm{NF}-\kappa \mathrm{B})$ signalling when cells are treated with BDNF, mediating neuronal survival (Sniderhan et al., 2008). In support of these findings, Kidins220/ARMS ${ }^{-/-}$embryos show widespread cell death in the central nervous system (CNS) and peripheral nervous system (PNS) and die at birth (Cesca et al., 2011; Cesca et al., 2012). Remarkably, Kidins220/ARMS is one of the few proteins that is selectively required for the sustained activation of MAPK signalling, whereas most of the other factors act in both transient and sustained signalling.

Because of the role Kidins220/ARMS has in survival pathways such as MAPK signalling, it is recognised as a potential oncogene. Accordingly, Kidins220/ARMS prevents stressinduced apoptosis in melanoma cells and contributes to tumour progression (Liao et al., 2007; Liao et al., 2011).

\section{Intracellular trafficking of Kidins220/ARMS}

Intracellular traffic of Kidins220/ARMS is mediated through a direct binding of KIM to KLC-1 and KLC-2, and is important in ensuring a correct response to neurotrophic stimuli in the neuronal model cell line PC12 (Bracale et al., 2007). The KIM motif of Kidins220/ARMS does not bear sequence similarities with other KLC-binding proteins (Bracale et al., 2007; Dodding et al., 2011). Similarly, the part of KLC that interacts with KIM has so far not been implicated in cargo recognition, suggesting that - through its C-terminal region - KLC recruits other proteins, such as 14-3-3 protein (Ichimura et al., 2002) or Jun Nterminal kinase (JNK)-interacting proteins (JIPs) (Verhey et al., 2001). Furthermore, overexpression of Kidins220/ARMS does not interfere with the trafficking of other kinesin-1 cargoes (Bracale et al., 2007; Hammond et al., 2008). The Kidins220/ ARMS-kinesin-1 complex might, therefore, constitute a modular scaffold for the assembly of larger protein complexes, in which single components associate with KLC as well as with the other domains of Kidins220/ARMS. Kidins220/ARMS might link motor proteins to inactive signalling complexes in order to mediate their targeting to specific domains of the plasma membrane. Once these complexes have been delivered to their final destination, they would become activated upon exposure to trophic stimuli.

The trafficking of Kidins220/ARMS to the plasma membrane relies on PKD activity (Sanchez-Ruiloba et al., 2006). PKD is a serine/threonine kinase involved in several cellular processes, such as cell proliferation and Golgi-complex trafficking (Van Lint et al., 2002). Kidins220/ARMS constitutively interacts with PKD and is phosphorylated by this kinase on serine 919 upon stimulation with phorbol ester (Iglesias et al., 2000). Kidins220/ ARMS associates with membrane microdomains at the leading edge of motile immature dendritic cells (Riol-Blanco et al., 2004), of PC12 cells and of primary cortical neurons (CabreraPoch et al., 2004). This lipid-microdomain-associated pool of Kidins220/ARMS colocalises with PKD. In addition, Kidins220/ ARMS and PKD are both present in the trans-Golgi network (TGN). The expression of a kinase-dead form of PKD alters the distribution of Kidins220/ARMS, causing its accumulation in intracellular structures that contain TGN markers. PKD activity controls Kidins220/ARMS trafficking to the plasma membrane through the phosphorylation-dependent recruitment of PDZ proteins at the TGN (Sanchez-Ruiloba et al., 2006). Therefore, 
the interaction with PKD could regulate the formation of signalling platforms that contain Kidins220/ARMS and one or more membrane receptors.

\section{Kidins220/ARMS regulates cytoskeletal remodelling and neuronal differentiation}

The function of neurons greatly depends on their highly polarised morphology, which is established during development (da Silva and Dotti, 2002). Neurotrophins and other growth factors induce rearrangements of the cytoskeleton at growth cones and changes in gene expression (Huber et al., 2003), which need to be highly coordinated. Kidins220/ARMS is ideally suited to fulfil this role, because it is implicated in neurotrophin signalling and interacts with cytoskeletal components (Higuero et al., 2010; Neubrand et al., 2010; Park et al., 2010). Neurite outgrowth requires the formation of F-actin (Huber et al., 2003), and Kidins220/ARMS colocalises with F-actin in NGF-differentiated PC12 cells (Neubrand et al., 2010; Park et al., 2010) and hippocampal neurons (Higuero et al., 2010). Interestingly, the amount of Factin at growth cones correlates with the amount of Kidins220/ ARMS present at these sites (Higuero et al., 2010), indicating the importance of Kidins220/ARMS in cytoskeletal remodelling in developing neurons.

Park and colleagues recently characterised an interaction between Kidins220/ARMS and septin 5 (Park et al., 2010), a protein involved in cytoskeletal organisation and membrane tubulation (Tanaka-Takiguchi et al., 2009). Independently, we reported that Kidins220/ARMS binds and activates Trio (Neubrand et al., 2010), a RhoGEF that promotes neurite outgrowth through cytoskeletal remodelling (Dickson, 2001; Estrach et al., 2002; Govek et al., 2005). In NGF-stimulated PC12 cells, this characteristic of Trio has been linked to its first GEF domain, which activates the small GTPases Rac1 and RhoG (Bateman and Van Vactor, 2001; Estrach et al., 2002). This activity of the GEF domain is regulated by the flanking SH3 and spectrin domains of Trio. Crucially, Kidins220/ARMS binds to the latter region through its $\mathrm{N}$-terminal ankyrin repeats (Neubrand et al., 2010). This interaction is important for the function of Trio, as overexpression of this domain causes widespread activation of Rac1. Because a localised activation of Rac1 at neurite tips is necessary for neurite extension (Aoki et al., 2004), the overexpression of the ankyrin repeats inhibits neurite outgrowth in PC12 cells and hippocampal neurons (Neubrand et al., 2010).

In addition to the actin cytoskeleton, Kidins220/ARMS interacts with microtubules by binding tubulin, the microtubule-associated proteins $1 \mathrm{a}, 1 \mathrm{~b}$ and 2 (MAP1a, MAP1b and MAP2, respectively), and the stathmin family members SCG10 and SCLIP (also known as STMN2 and STMN3, respectively) (Higuero et al., 2010). These factors have a wellestablished role in neuronal morphogenesis (Poulain and Sobel, 2009) and their ability to modulate microtubule dynamics is phosphorylation dependent (Owen and Gordon-Weeks, 2003). In this context, Higuero and colleagues found a reduction in the phosphorylation of stathmin and MAP1b in Kidins220/ARMS knockdown neurons (Higuero et al., 2010). Interestingly, downregulation of Kidins220/ARMS in young hippocampal neurons favours the formation of multiple axon-like processes, whereas its knockdown in cells at later stages of differentiation leads to an aberrant dendritic arbour (Higuero et al., 2010). These results have been confirmed in Kidins220/ARMS ${ }^{-1-}$ neurons, in which longer axons and a simplified dendritic network were detected when compared with wild-type cells (Cesca et al., 2012).

In summary, Kidins220/ARMS controls axonal and dendritic maturation by directly modulating cytoskeletal dynamics and, in parallel, by inducing changes in sustained MAPK-dependent gene expression.

\section{Effects of Kidins220/ARMS on neuronal activity}

Neurotrophins are required for synaptogenesis and neuronal maturation (Martinez et al., 1998; Poo, 2001). Interestingly, the expression levels of Kidins220/ARMS are highly regulated during these processes (Cortes et al., 2007; Higuero et al., 2010). In hippocampal neurons, Kidins220/ARMS is more abundant during early stages of differentiation compared with later stages, when more synapses are present and neuronal activity is higher (Cortes et al., 2007; Higuero et al., 2010).

These findings support recent results suggesting that Kidins220/ARMS expression negatively regulates the membrane levels of the GluA1 subunit of the $\alpha$-amino-3hydroxy-5-methyl-4-isoxazolepropionic acid (AMPA) glutamate receptor (Arevalo et al., 2010). During neuronal development, this receptor is targeted to the cell surface to create a mature glutamatergic synapse (Hall and Ghosh, 2008). In the adult brain, GluA2 is the main AMPA receptor subunit, and the incorporation of the GluA1 subunit results in the formation of $\mathrm{Ca}^{2+}$-permeable AMPA receptors that lack GluA2 (Bassani et al., 2009), which are crucial in establishing and maintaining synaptic plasticity (Man, 2011). Downregulation of Kidins220/ARMS by using RNAi or in Kidins220/ARMS ${ }^{+/-}$mice leads to an increase of GluA1 at the plasma membrane, which can be also detected as a rise in AMPA-receptor-mediated currents (Arevalo et al., 2010). In parallel, reduced levels of Kidins220/ARMS determine an increase in phosphorylation of GluA1 at Serine 831, which is associated with an enhanced receptor conductance (Benke et al., 1998; Derkach et al., 1999). Interestingly, GluA1 but not GluA2 co-immunoprecipitates with Kidins220/ARMS (Arevalo et al., 2010). These results suggest that, during development, in regions characterised by high levels of Kidins220/ARMS, GluA1containing AMPA receptors are retained intracellularly through an interaction with Kidins220/ARMS. When neurons mature and synapses are formed, Kidins220/ARMS levels decrease, allowing for the surface expression of GluA1 and the establishment of synaptic strength. The GluA1-specific interaction of Kidins220/ ARMS therefore suggests that this protein indirectly modulates $\mathrm{Ca}^{2+}$ homeostasis at the nerve terminal, and has a role in synaptic plasticity.

Kidins220/ARMS levels correlate with the activity of the neuronal network. In mature neuronal cultures, Kidins220/ARMS also associates with NMDA receptors (Lopez-Menendez et al., 2009). Upon overstimulation of the NMDA receptor, for example during excitotoxicity or when neurons are depolarised, activitydependent $\mathrm{Ca}^{2+}$ influx through NMDA receptors leads to a decrease in Kidins220/ARMS levels owing to transcriptional downregulation (Lopez-Menendez et al., 2009) and protein cleavage by calpain (Lopez-Menendez et al., 2009; Wu et al., 2010). Because Kidins220/ARMS knockdown causes a decrease in the amount of phosphorylated MAPK (Lopez-Menendez et al., 2009), a reduction in the expression of Kidins220/ARMS might contribute to neuronal death through a decrease in MAPK signalling. Accordingly, in an animal model of cerebral ischemia, Kidins220/ARMS levels correlate with the extent of neuronal cell 
death, which was attributed to excitotoxic NMDA-receptor activation (Lopez-Menendez et al., 2009). Altogether, these findings indicate that the amount of Kidins220/ARMS is tightly controlled and has a fundamental role in neuronal survival, both under basal and excitotoxic conditions. In addition to sites of calpain cleavage (Lopez-Menendez et al., 2009; Wu et al., 2010), sites of caspase-3-dependent cleavage ( $\mathrm{Ju}$ et al., 2007) and of ubiquitylation (Kim et al., 2011) are present in the Kidins220/ ARMS sequence. Further studies are therefore needed for a better understanding of the molecular mechanisms that regulate the turnover of Kidins220/ARMS.

Both excitatory and inhibitory circuits are influenced by Kidins220/ARMS. A decrease of Kidins220/ARMS in hippocampal neurons results in a lesser release of $\gamma$-aminobutyric acid (GABA), whereas overexpression of Kidins220/ARMS has the opposite effect, probably because of a mechanism that occurs at the presynaptic terminal (Sutachan et al., 2010). Our recent work, using cultured neurons from Kidins220/ARMS ${ }^{-1-}$ mouse embryos, indicates that Kidins220/ARMS regulates the recovery of synaptic strength at inhibitory GABAergic synapses, whereas inhibitory basal transmission is not affected (Scholz-Starke et al., 2012). These findings are in line with previous data that show a reciprocal relationship between neuronal activity and the level of Kidins220/ARMS (Cortes et al., 2007). Interestingly, incubation of hippocampal neurons with either BDNF or the neuronal-activitymodulating tetrodotoxin causes an increase of Kidins220/ARMS expression, but combination of these treatments does not have an additive effect (Cortes et al., 2007). This observation suggests that neurotrophin- or activity-dependent changes control Kidins220/ ARMS levels by acting on the same pathway. The involvement of Kidins220/ARMS in neurotrophin-dependent synaptic plasticity is further confirmed by the finding that BDNF-induced potentiation of excitatory postsynaptic currents is impaired in Kidins220/ $\mathrm{ARMS}^{-1-}$ neurons (Cesca et al., 2012). Altogether, these results suggest that Kidins220/ARMS functions as a neuronal maturation and activity sensor.

Most of these data were initially obtained by acute down- or upregulation of Kidins220/ARMS, and have subsequently been confirmed using Kidins220/ARMS ${ }^{+/-}$mice, which express 30 $40 \%$ less protein than wild-type animals. In this mouse strain, both basal synaptic neurotransmission and long-term potentiation (LTP) are increased (Wu et al., 2009; Wu et al., 2010). In addition, they show defects in spatial memory formation (Duffy et al., 2011), a process in which a correct balance between LTP and long-term depression (LTD) is paramount (Kemp and Manahan-Vaughan, 2007; Ge et al., 2010). Because homozygous Kidins220/ARMS ${ }^{-1-}$ embryos die at birth, future analysis of conditional Kidins220/ARMS ${ }^{-1-}$ mouse lines will help to further our understanding on the role of this protein in synaptic plasticity and higher brain functions.

Neuronal activity also mediates structural modifications that are important for development of the CNS and for synaptic plasticity. BDNF is an important activity-dependent factor, which induces dendritic growth and controls dendritic spine morphogenesis (Cohen-Cory and Fraser, 1995; McAllister et al., 1995; Horch and Katz, 2002; Liu et al., 2007). Kidins220/ $\mathrm{ARMS}^{-/-}$embryos and adult Kidins220/ARMS ${ }^{+-}$mice display defects in dendritic growth and branching (Wu et al., 2009; Cesca et al., 2012), indicating that Kidins220/ARMS is important in BDNF-induced dendritic development. Dendritic branching correlates with the stabilisation of the synapse, which can be assessed by measuring dendritic spine turnover. Indeed, spine stability is reduced in Kidins220/ARMS ${ }^{+/-}$mice (Wu et al., 2009), suggesting a role for Kidins220/ARMS in cytoskeletal remodelling events that underly the homeostatic control of these postsynaptic structures. In support of this idea, Kidins220/ARMS interacts with kalirin (Neubrand et al., 2010), a RhoGEF that controls the signalling events downstream of EphB, NMDA and AMPA receptors, which modulate the formation of dendritic spines (Penzes and Jones, 2008).

\section{Kidins220/ARMS at the crossroad of several signalling streams}

Kidins220/ARMS is not only involved in Trk, NMDA and AMPA receptor signalling, but it is also a downstream target of ephrins (Kong et al., 2001; Luo et al., 2005) and interacts with VEGFR (Cesca et al., 2012). Through its interaction with VEGFR, Kidins220/ARMS might have a role in vascular development, connecting neurotrophins with VEGF signalling. Indeed, Kidins220/ARMS ${ }^{-1-}$ embryos reveal an abnormal vascular pattern in the brain (Cesca et al., 2012), similar to that observed in mice lacking neuropilin-1, a co-receptor of VEGFR (Gu et al., 2003). Additionally, Kidins220/ARMS is phosphorylated when cells that express EphB2 are stimulated with ephrin-B2 (Kong et al., 2001). Kidins220/ARMS also enhances EphA4 signalling, which is triggered by ephrin-A1 during the formation of the neuromuscular junction through its binding to $\alpha$-syntrophin. Moreover, Kidins220/ARMS coimmunoprecipitates with and is phosphorylated by the EphA4 receptor (Luo et al., 2005).

TrkB, EphA4, EphB1, EphB2, EphB3, NMDA and AMPA receptors are all implicated in synaptogenesis and dendritic spine maturation (Constantine-Paton and Cline, 1998; Poo, 2001; Klein, 2009; Lai and Ip, 2009; McKinney, 2010). Interestingly, these receptors display a substantial crosstalk among each other; the NMDA receptor is phosphorylated upon BDNF stimulation (Lin et al., 1998) and the EphB extracellular domain interacts directly with the NMDA receptor (Dalva et al., 2000; Henderson et al., 2001). In addition, ephrin-B-mediated activation of EphB leads to NMDA-receptor-dependent $\mathrm{Ca}^{2+}$ influx (Takasu et al., 2002), which might influence the level of Kidins220/ARMS protein synthesis and its downstream signalling. Altogether, these data suggest that Kidins220/ARMS controls synaptic formation and stability by acting as a common downstream target of TrkB, NMDA, AMPA and EphB receptors. Fig. 3 summarises the present knowledge regarding the function of Kidins220/ARMS at synapses, both in the presynaptic compartment and in dendritic spines. Future studies aimed at increasing our understanding of these interactions are likely to reveal new aspects of the molecular mechanisms underlying synapse formation.

\section{Future perspectives}

Kidins220/ARMS orchestrates different functions in the nervous system as well as in other tissues. In addition to the neuronal phenotypes observed in the CNS and PNS, Kidins220/ARMS ${ }^{-/-}$ embryos show cardiac malformations and severe defects in vascular development (Cesca et al., 2011; Cesca et al., 2012). Several reports also indicate a role for Kidins220/ARMS in the immune system (Riol-Blanco et al., 2004; Ni et al., 2010; JeanMairet et al., 2011; Ni et al., 2011). With full and conditional knockout mouse lines to hand, it will now be possible to carry out a functional analysis of this versatile protein in tissues other than 

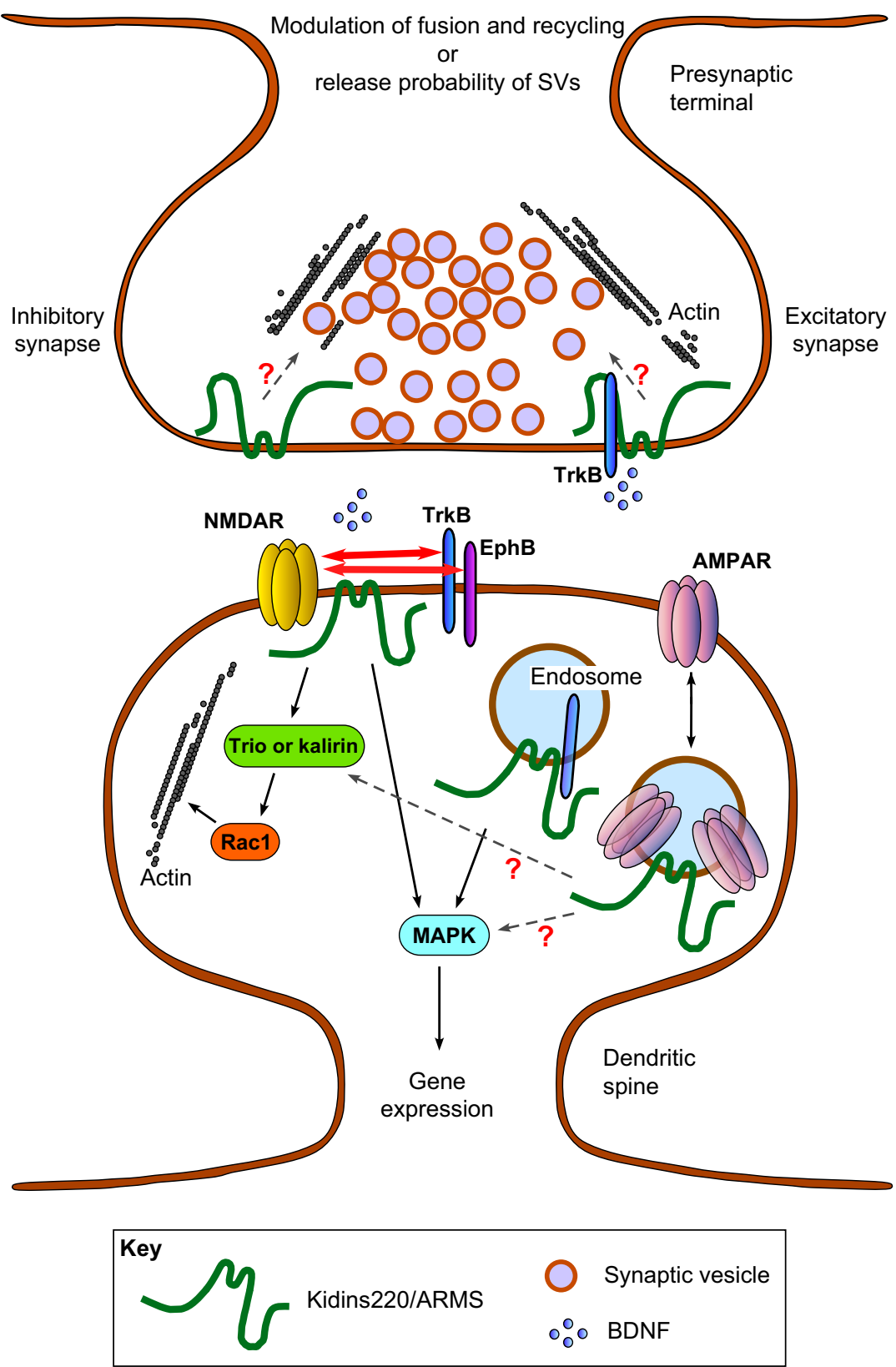

Fig. 3. Role of Kidins220/ARMS at synapses. At excitatory synapses, Kidins220/ARMS mediates BDNF-induced potentiation, whereas at inhibitory synapses, it is involved in neurotrophin-independent short-term plasticity. In both cases, the observed cellular phenotypes can be explained by alterations of synaptic vesicle fusion and recycling, or changes in the release probabilty. The precise molecular mechanisms at the basis of this regulation are presently unclear (red question marks). In dendritic spines, during synapse formation, NMDA, Trk and Eph receptors undergo substantial crosstalk with each other (red arrows), with Kidins220/ARMS as a possible common downstream target. Kidins220/ARMS signals to the actin cytoskeleton via Rac1 through its interaction with Trio or kalirin. In parallel, Kidins220/ARMS activates neuronal survival and differentiation by the sustained MAPK pathway, which mainly takes place on endosomal compartments. Kidins220/ ARMS also regulates the targeting of the GluA1 subunit of the AMPA receptor to the cell surface. However, when and how Kidins220/ARMS is internalised is presently unknown. Kidins220/ARMS might signal to Trio (or kalirin) and MAPK from an AMPA-receptor-containing endocytic compartment (dashed arrows), but this hypothesis requires further investigation (indicated by red question marks). AMPAR, AMPA receptor; NMDAR, NMDA receptor. the nervous system. These tools will also allow the differentiation of cell-autonomous and non-autonomous roles of Kidins220/ ARMS in vivo. For example, extensive cell death was reported in brains of Kidins220/ARMS ${ }^{-1-}$ embryos, leading to abnormal ventricle enlargement (Cesca et al., 2011; Cesca et al., 2012). Ablation of Kidins220/ARMS only in the nervous system, however, does not yield the high level of cell death observed in Kidins220/ARMS ${ }^{-1-}$ embryos (Cesca et al., 2012). Because the apoptotic regions in Kidins220/ARMS ${ }^{-1-}$ brains correspond to some of the areas that display abnormal vascular patterning, defective vascularisation might contribute, at least in part, to the instances of neuronal death observed in these areas.

Like neurotrophins and their receptors, Kidins220/ARMS is involved in regulating the equilibrium between cell death and cell survival by affecting signalling pathways that act as principal regulators of this process, such as the ERK pathway (Martin and Clark, 2007). Indeed, Trk receptors were originally identified as oncogenes (Martin-Zanca et al., 1986). It is therefore not surprising that Kidins220/ARMS was suggested to have a role as an oncogene and that it is overexpressed in melanoma, a skin cancer of neural crest origin (Liao et al., 2007; Liao et al. 2011) and possibly in other types of cancer. Understanding how to control the activity of Kidins220/ARMS during tumour progression, for example by specifically targeting its NTPase domain, represents a possible avenue for therapeutic intervention and an attractive means to study the balance between death and survival signals. The involvement of Kidins220/ARMS in the vascular development within specific areas of the brain is also very appealing, both in the context of cancer therapy and following ischemic insults, whereby a boost in neovascularisation 
might be beneficial. Future research in these areas can reveal exciting new directions for a better understanding of signal integration at cellular and tissue levels, and might offer new translational opportunities in important fields of medicine.

\section{Acknowledgements}

We thank P. Chakravarty for help with the bioinformatics analyses, and C.L. Thomas, A. Yabe, N. Schmieg and J. Scholz-Starke for critical reading of the manuscript.

\section{Funding}

This study was supported by research grants from: Cancer Research UK (to G.S.); the Italian Institute of Technology (to F.C. and F.B.); the Italian Ministry of University and Research [2008T4ZCNL grant number 2008T4ZCNL to F.B.]; the Compagnia di San Paolo, Torino (to F.B.); Telethon-Italy [grant number GGP09134 to F.B.] and the Spanish Ministry of Science and Innovation [grant number JCI-200801843 to V.N.].

\section{References}

Aoki, K., Nakamura, T. and Matsuda, M. (2004). Spatio-temporal regulation of Rac and $\mathrm{Cdc} 42$ activity during nerve growth factor-induced neurite outgrowth in PC12 cells. J. Biol. Chem. 279, 713-719.

Aravind, L., Iyer, L. M., Leipe, D. D. and Koonin, E. V. (2004). A novel family of Ploop NTPases with an unusual phyletic distribution and transmembrane segment inserted within the NTPase domain. Genome Biol. 5, R30.

Arevalo, J. C., Yano, H., Teng, K. K. and Chao, M. V. (2004). A unique pathway for sustained neurotrophin signaling through an ankyrin-rich membrane-spanning protein EMBO J. 23, 2358-2368

Arevalo, J. C., Pereira, D. B., Yano, H., Teng, K. K. and Chao, M. V. (2006). Identification of a switch in neurotrophin signaling by selective tyrosine phosphorylation. J. Biol. Chem. 281, 1001-1007.

Arevalo, J. C., Wu, S. H., Takahashi, T., Zhang, H., Yu, T., Yano, H., Milner, T. A., Tessarollo, L., Ninan, I., Arancio, O. et al. (2010). The ARMS/Kidins220 scaffold protein modulates synaptic transmission. Mol. Cell. Neurosci. 45, 92-100.

Bassani, S., Valnegri, P., Beretta, F. and Passafaro, M. (2009). The GLUR2 subunit of AMPA receptors: synaptic role. Neuroscience 158, 55-61.

Bateman, J. and Van Vactor, D. (2001). The Trio family of guanine-nucleotideexchange factors: regulators of axon guidance. J. Cell Sci. 114, 1973-1980.

Benke, T. A., Luthi, A., Isaac, J. T. and Collingridge, G. L. (1998). Modulation of AMPA receptor unitary conductance by synaptic activity. Nature 393, 793-797.

Bibel, M. and Barde, Y. A. (2000). Neurotrophins: key regulators of cell fate and cell shape in the vertebrate nervous system. Genes Dev. 14, 2919-2937.

Bracale, A., Cesca, F., Neubrand, V. E., Newsome, T. P., Way, M. and Schiavo, G. (2007). Kidins220/ARMS is transported by a kinesin-1-based mechanism likely to be involved in neuronal differentiation. Mol. Biol. Cell 18, 142-152.

Bronfman, F. C. and Fainzilber, M. (2004). Multi-tasking by the p75 neurotrophin receptor: sortilin things out? EMBO Rep. 5, 867-871.

Cabrera-Poch, N., Sanchez-Ruiloba, L., Rodriguez-Martinez, M. and Iglesias, T. (2004). Lipid raft disruption triggers protein kinase C and Src-dependent protein kinase D activation and Kidins220 phosphorylation in neuronal cells. J. Biol. Chem. 279, 28592-28602

Cesca, F., Yabe, A., Spencer-Dene, B., Arrigoni, A., Al-Qatari, M., Henderson, D., Phillips, H., Koltzenburg, M., Benfenati, F. and Schiavo, G. (2011). Kidins220/ ARMS is an Essential Modulator of Cardiovascular and Nervous System Development. Cell Death Dis. 2, e226.

Cesca, F., Yabe, A., Spencer-Dene, B., Scholz-Starke, J., Medrihan, L., Maden, C. H., Gerhardt, H., Orriss, I. R., Baldelli, P., Al-Qatari, M. et al. (2012) Kidins220/ARMS Mediates the Integration of the Neurotrophin and VEGF Pathways in the Vascular and Nervous Systems. Cell Death Differ., 2, 194-208.

Chang, M. S., Arevalo, J. C. and Chao, M. V. (2004). Ternary complex with Trk, p75, and an ankyrin-rich membrane spanning protein. J. Neurosci Res. 78, 186-192.

Chao, M. V. (2003). Neurotrophins and their receptors: a convergence point for many signalling pathways. Nat Rev. Neurosci. 4, 299-309.

Clary, D. O. and Reichardt, L. F. (1994). An alternatively spliced form of the nerve growth factor receptor TrkA confers an enhanced response to neurotrophin 3. Proc Natl. Acad. Sci. USA 91, 11133-11137.

Cohen-Cory, S. and Fraser, S. E. (1995). Effects of brain-derived neurotrophic factor on optic axon branching and remodelling in vivo. Nature 378, 192-196.

Constantine-Paton, M. and Cline, H. T. (1998). LTP and activity-dependent synaptogenesis: the more alike they are, the more different they become. Curr. Opin. Neurobiol. 8, 139-148.

Cortes, R. Y., Arevalo, J. C., Magby, J. P., Chao, M. V. and Plummer, M. R. (2007) Developmental and activity-dependent regulation of ARMS/Kidins220 in cultured rat hippocampal neurons. Dev. Neurobiol. 67, 1687-1698.

Dalva, M. B., Takasu, M. A., Lin, M. Z., Shamah, S. M., Hu, L., Gale, N. W. and Greenberg, M. E. (2000). EphB receptors interact with NMDA receptors and regulate excitatory synapse formation. Cell 103, 945-956. da Silva, J. S. and Dotti, C. G. (2002). Breaking the neuronal sphere: regulation of the actin cytoskeleton in neuritogenesis. Nat. Rev. Neurosci. 3, 694-704.

Derkach, V., Barria, A. and Soderling, T. R. (1999). Ca2+/calmodulin-kinase II enhances channel conductance of alpha-amino-3-hydroxy-5-methyl-4-isoxazolepropionate type glutamate receptors. Proc. Natl. Acad. Sci. USA 96, 3269-3274.

Dickson, B. J. (2001). Rho GTPases in growth cone guidance. Curr. Opin. Neurobiol. 11, $103-110$

Dodding, M. P., Mitter, R., Humphries, A. C. and Way, M. (2011). A kinesin-1 binding motif in vaccinia virus that is widespread throughout the human genome. EMBO J., 30, 4523-4538

Drescher, U. (2002). Eph family functions from an evolutionary perspective. Curr Opin. Genet. Dev. 12, 397-402.

Duffy, A. M., Schaner, M. J., Wu, S. H., Staniszewski, A., Kumar, A., Arevalo, J. C., Arancio, O., Chao, M. V. and Scharfman, H. E. (2011). A selective role for ARMS Kidins220 scaffold protein in spatial memory and trophic support of entorhinal and frontal cortical neurons. Exp. Neurol. 229, 409-420.

Estrach, S., Schmidt, S., Diriong, S., Penna, A., Blangy, A., Fort, P. and Debant, A. (2002). The Human Rho-GEF trio and its target GTPase RhoG are involved in the NGF pathway, leading to neurite outgrowth. Curr. Biol. 12, 307-312.

Fitzgerald, M., Buckley, A., Lukehurst, S. S., Dunlop, S. A., Beazley, L. D. and Rodger, J. (2008). Neurite responses to ephrin-A5 modulated by BDNF: evidence for TrkB-EphA interactions. Biochem. Biophys. Res. Commun. 374, 625-630.

Ge, Y., Dong, Z., Bagot, R. C., Howland, J. G., Phillips, A. G., Wong, T. P. and Wang, Y. T. (2010). Hippocampal long-term depression is required for the consolidation of spatial memory. Proc. Natl. Acad. Sci. USA 107, 16697-16702.

Govek, E. E., Newey, S. E. and Van Aelst, L. (2005). The role of the Rho GTPases in neuronal development. Genes Dev. 19, 1-49.

Gu, C., Rodriguez, E. R., Reimert, D. V., Shu, T., Fritzsch, B., Richards, L. J., Kolodkin, A. L. and Ginty, D. D. (2003). Neuropilin-1 conveys semaphorin and VEGF signaling during neural and cardiovascular development. Dev. Cell 5, 45-57.

Hall, B. J. and Ghosh, A. (2008). Regulation of AMPA receptor recruitment at developing synapses. Trends Neurosci. 31, 82-89.

Hammond, J. W., Griffin, K., Jih, G. T., Stuckey, J. and Verhey, K. J. (2008). Cooperative versus independent transport of different cargoes by Kinesin-1. Traffic 9, 725-741.

Hapner, S. J., Boeshore, K. L., Large, T. H. and Lefcort, F. (1998). Neural differentiation promoted by truncated trkC receptors in collaboration with p75(NTR). Dev. Biol. 201, 90-100.

Henderson, J. T., Georgiou, J., Jia, Z., Robertson, J., Elowe, S., Roder, J. C. and Pawson, T. (2001). The receptor tyrosine kinase EphB2 regulates NMDA-dependent synaptic function. Neuron 32, 1041-1056.

Higgins, C. F., Gallagher, M. P., Mimmack, M. L. and Pearce, S. R. (1988). A family of closely related ATP-binding subunits from prokaryotic and eukaryotic cells. Bioessays 8, 111-116.

Higuero, A. M., Sanchez-Ruiloba, L., Doglio, L. E., Portillo, F., Abad-Rodriguez, J., Dotti, C. G. and Iglesias, T. (2010). Kidins220/ARMS modulates the activity of microtubule-regulating proteins and controls neuronal polarity and development. J. Biol. Chem. 285, 1343-1357.

Hisata, S., Sakisaka, T., Baba, T., Yamada, T., Aoki, K., Matsuda, M. and Takai, Y. (2007). Rap1-PDZ-GEF1 interacts with a neurotrophin receptor at late endosomes, leading to sustained activation of Rapl and ERK and neurite outgrowth. J. Cell. Biol. 178, 843-860.

Horch, H. W. and Katz, L. C. (2002). BDNF release from single cells elicits local dendritic growth in nearby neurons. Nat. Neurosci. 5, 1177-1184.

Huang, E. J. and Reichardt, L. F. (2001). Neurotrophins: roles in neuronal development and function. Annu. Rev. Neurosci. 24, 677-736.

Huang, E. J. and Reichardt, L. F. (2003). Trk receptors: roles in neuronal signal transduction. Аnпи. Rev. Biochem. 72, 609-642.

Huber, A. B., Kolodkin, A. L., Ginty, D. D. and Cloutier, J. F. (2003). Signaling at the growth cone: ligand-receptor complexes and the control of axon growth and guidance. Annu. Rev. Neurosci 26, 509-563.

Ichimura, T., Wakamiya-Tsuruta, A., Itagaki, C., Taoka, M., Hayano, T., Natsume, T. and Isobe, T. (2002). Phosphorylation-dependent interaction of kinesin light chain 2 and the 14-3-3 protein. Biochemistry 41, 5566-5572.

Iglesias, T., Cabrera-Poch, N., Mitchell, M. P., Naven, T. J., Rozengurt, E. and Schiavo, G. (2000). Identification and cloning of Kidins220, a novel neuronal substrate of protein kinase D. J. Biol. Chem. 275, 40048-40056.

Jean-Mairet, R. M., Lopez-Menendez, C., Sanchez-Ruiloba, L., Sacristan, S., Rodriguez-Martinez, M., Riol-Blanco, L., Sanchez-Mateos, P., Sanchez-Madrid, F., Rodriguez-Fernandez, J. L., Campanero, M. R. et al. (2011). The neuronal protein Kidins220/ARMS associates with ICAM-3 and other uropod components and regulates T-cell motility. Eur. J. Immunol. 41, 1035-1046.

Ju, W., Valencia, C. A., Pang, H., Ke, Y., Gao, W., Dong, B. and Liu, R. (2007) Proteome-wide identification of family member-specific natural substrate repertoire of caspases. Proc. Natl. Acad. Sci. USA 104, 14294-14299.

Kemp, A. and Manahan-Vaughan, D. (2007). Hippocampal long-term depression master or minion in declarative memory processes? Trends Neurosci. 30, 111-118.

Kim, W., Bennett, E. J., Huttlin, E. L., Guo, A., Li, J., Possemato, A., Sowa, M. E., Rad, R., Rush, J., Comb, M. J. et al. (2011). Systematic and Quantitative Assessment of the Ubiquitin-Modified Proteome. Mol. Cell, 44, 325-340.

Klein, R. (2009). Bidirectional modulation of synaptic functions by Eph/ephrin signaling. Nat. Neurosci. 12, 15-20. 
Kong, H., Boulter, J., Weber, J. L., Lai, C. and Chao, M. V. (2001). An evolutionarily conserved transmembrane protein that is a novel downstream target of neurotrophin and ephrin receptors. $J$. Neurosci. 21, 176-185.

Kuruvilla, R., Ye, H. and Ginty, D. D. (2000). Spatially and functionally distinct roles of the PI3-K effector pathway during NGF signaling in sympathetic neurons. Neuron 27, 499-512.

Lai, K. O. and Ip, N. Y. (2009). Synapse development and plasticity: roles of ephrin/ Eph receptor signaling. Curr. Opin. Neurobiol. 19, 275-283.

Lee, F. S., Kim, A. H., Khursigara, G. and Chao, M. V. (2001). The uniqueness of being a neurotrophin receptor. Curr. Opin. Neurobiol. 11, 281-286.

Liao, Y. H., Hsu, S. M. and Huang, P. H. (2007). ARMS depletion facilitates UV irradiation induced apoptotic cell death in melanoma. Cancer Res. 67, 11547-11556.

Liao, Y. H., Hsu, S. M., Yang, H. L., Tsai, M. S. and Huang, P. H. (2011). Upregulated ankyrin repeat-rich membrane spanning protein contributes to tumour progression in cutaneous melanoma. Br. J. Cancer 104, 982-988.

Lin, S. Y., Wu, K., Levine, E. S., Mount, H. T., Suen, P. C. and Black, I. B. (1998). BDNF acutely increases tyrosine phosphorylation of the NMDA receptor subunit 2B in cortical and hippocampal postsynaptic densities. Brain Res. Mol. Brain Res. 55, 2027

Liu, X., Grishanin, R. N., Tolwani, R. J., Renteria, R. C., Xu, B., Reichardt, L. F. and Copenhagen, D. R. (2007). Brain-derived neurotrophic factor and TrkB modulate visual experience-dependent refinement of neuronal pathways in retina. J. Neurosci. 27, 7256-7267.

Lopez-Menendez, C., Gascon, S., Sobrado, M., Vidaurre, O. G., Higuero, A. M., Rodriguez-Pena, A., Iglesias, T. and Diaz-Guerra, M. (2009). Kidins220/ARMS downregulation by excitotoxic activation of NMDARs reveals its involvement in neuronal survival and death pathways. J. Cell Sci. 122, 3554-3565.

Luo, S., Chen, Y., Lai, K. O., Arevalo, J. C., Froehner, S. C., Adams, M. E., Chao, M. V. and Ip, N. Y. (2005). \{alpha\}-Syntrophin regulates ARMS localization at the neuromuscular junction and enhances EphA4 signaling in an ARMS-dependent manner. J. Cell Biol. 169, 813-824.

Man, H. Y. (2011). GluA2-lacking, calcium-permeable AMPA receptors--inducers of plasticity? Curr. Opin. Neurobiol. 21, 291-298.

Marler, K. J., Becker-Barroso, E., Martinez, A., Llovera, M., Wentzel, C., Poopalasundaram, S., Hindges, R., Soriano, E., Comella, J. and Drescher, U. (2008). A TrkB/EphrinA interaction controls retinal axon branching and synaptogenesis. J. Neurosci. 28, 12700-12712.

Marshall, C. J. (1995). Specificity of receptor tyrosine kinase signaling: transient versus sustained extracellular signal-regulated kinase activation. Cell 80, 179-185.

Martin, S. J. and Clark, R. E. (2007). The rodent hippocampus and spatial memory: from synapses to systems. Cell Mol. Life Sci. 64, 401-431.

Martinez, A., Alcantara, S., Borrell, V., Del Rio, J. A., Blasi, J., Otal, R., Campos, N., Boronat, A., Barbacid, M., Silos-Santiago, I. et al. (1998). TrkB and TrkC signaling are required for maturation and synaptogenesis of hippocampal connections. J. Neurosci. 18, 7336-7350.

Martin-Zanca, D., Mitra, G., Long, L. K. and Barbacid, M. (1986). Molecular characterization of the human trk oncogene. Cold Spring Harb Symp. Quant. Biol. 51, 983-992.

McAllister, A. K., Lo, D. C. and Katz, L. C. (1995). Neurotrophins regulate dendritic growth in developing visual cortex. Neuron 15, 791-803.

McKinney, R. A. (2010). Excitatory amino acid involvement in dendritic spine formation, maintenance and remodelling. J. Physiol. 588, 107-116.

Mellott, D. O. and Burke, R. D. (2008). The molecular phylogeny of eph receptors and ephrin ligands. BMC Cell Biol. 9, 27.

Neubrand, V. E., Thomas, C., Schmidt, S., Debant, A. and Schiavo, G. (2010). Kidins220/ARMS regulates Rac1-dependent neurite outgrowth by direct interaction with the RhoGEF Trio. J. Cell Sci. 123, 2111-2123.

Ni, X., Li, X., Fang, X., Li, N., Cui, W. and Zhang, B. (2010). NGF/TrkA-mediated Kidins220/ARMS signaling activated in the allergic airway challenge in mice. Ann. Allergy Asthma Immunol. 105, 299-306.

Ni, X., Li, X., Fang, X., Li, N., Cui, W., Zhang, B. and Liu, Y. (2011). Kidins220/ ARMS contributes to airway inflammation and hyper-responsiveness in OVAsensitized mice. Respir. Physiol. Neurobiol. 175, 97-103.

Owen, R. and Gordon-Weeks, P. R. (2003). Inhibition of glycogen synthase kinase 3 beta in sensory neurons in culture alters filopodia dynamics and microtubule distribution in growth cones. Mol. Cell Neurosci. 23, 626-637.

Palko, M. E., Coppola, V. and Tessarollo, L. (1999). Evidence for a role of truncated trkC receptor isoforms in mouse development. J. Neurosci. 19, 775-782.
Paratcha, G. and Ledda, F. (2008). GDNF and GFRalpha: a versatile molecular complex for developing neurons. Trends Neurosci. 31, 384-391.

Park, H. J., Park, H. W., Lee, S. J., Arevalo, J. C., Park, Y. S., Lee, S. P., Paik, K. S., Chao, M. V. and Chang, M. S. (2010). Ankyrin repeat-rich membrane spanning/ Kidins 220 protein interacts with mammalian Septin 5. Mol. Cells 30, 143-148.

Penzes, P. and Jones, K. A. (2008). Dendritic spine dynamics--a key role for kalirin-7. Trends Neurosci. 31, 419-427.

Poo, M. M. (2001). Neurotrophins as synaptic modulators. Nat. Rev. Neurosci. 2, 24-32.

Poulain, F. E. and Sobel, A. (2009). The microtubule network and neuronal morphogenesis: Dynamic and coordinated orchestration through multiple players. Mol. Cell Neurosci. 43, 15-32.

Riol-Blanco, L., Iglesias, T., Sanchez-Sanchez, N., de la Rosa, G., Sanchez-Ruiloba, L., Cabrera-Poch, N., Torres, A., Longo, I., Garcia-Bordas, J., Longo, N. et al. (2004). The neuronal protein Kidins 220 localizes in a raft compartment at the leading edge of motile immature dendritic cells. Eur. J. Immunol. 34, 108-118.

Ruiz de Almodovar, C., Lambrechts, D., Mazzone, M. and Carmeliet, P. (2009). Role and therapeutic potential of VEGF in the nervous system. Physiol. Rev. 89, 607648 .

Sanchez-Ruiloba, L., Cabrera-Poch, N., Rodriguez-Martinez, M., Lopez-Menendez, C., Jean-Mairet, R. M., Higuero, A. M. and Iglesias, T. (2006). Protein kinase D intracellular localization and activity control kinase D-interacting substrate of 220$\mathrm{kDa}$ traffic through a postsynaptic density-95/discs large/zonula occludens-1-binding motif. J. Biol. Chem. 281, 18888-18900.

Schalm, S. S., Ballif, B. A., Buchanan, S. M., Phillips, G. R. and Maniatis, T. (2010). Phosphorylation of protocadherin proteins by the receptor tyrosine kinase Ret. Proc. Natl. Acad. Sci. USA 107, 13894-13899.

Scholz-Starke, J., Cesca, F, Schiavo, G, Benfenati, F. and Baldelli, P. (2012). Kidins220/ARMS is a novel modulator of short-term synaptic plasticity in hippocampal GABAergic neurons. PLOS ONE, in press.

Seipel, K., Eberhardt, M., Muller, P., Pescia, E., Yanze, N. and Schmid, V. (2004). Homologs of vascular endothelial growth factor and receptor, VEGF and VEGFR, in the jellyfish Podocoryne carnea. Dev. Dyn. 231, 303-312.

Shibuya, M. (2002). Vascular endothelial growth factor receptor family genes: when did the three genes phylogenetically segregate? Biol. Chem. 383, 1573-1579.

Sniderhan, L. F., Stout, A., Lu, Y., Chao, M. V. and Maggirwar, S. B. (2008). Ankyrin-rich membrane spanning protein plays a critical role in nuclear factor-kappa B signaling. Mol. Cell Neurosci. 38, 404-416.

Stoilov, P., Castren, E. and Stamm, S. (2002). Analysis of the human TrkB gene genomic organization reveals novel TrkB isoforms, unusual gene length, and splicing mechanism. Biochem. Biophys. Res. Commun. 290, 1054-1065.

Strohmaier, C., Carter, B. D., Urfer, R., Barde, Y. A. and Dechant, G. (1996). A splice variant of the neurotrophin receptor trkB with increased specificity for brainderived neurotrophic factor. EMBO J. 15, 3332-3337.

Sutachan, J. J., Chao, M. V. and Ninan, I. (2010). Regulation of inhibitory neurotransmission by the scaffolding protein ankyrin repeat-rich membrane spanning/ kinase D-interacting substrate of $220 \mathrm{kDa}$. J. Neurosci. Res. 88, 3447-3456.

Takasu, M. A., Dalva, M. B., Zigmond, R. E. and Greenberg, M. E. (2002). Modulation of NMDA receptor-dependent calcium influx and gene expression through EphB receptors. Science 295, 491-495.

Tanaka-Takiguchi, Y., Kinoshita, M. and Takiguchi, K. (2009). Septin-mediated uniform bracing of phospholipid membranes. Curr. Biol. 19, 140-145.

Van Lint, J., Rykx, A., Maeda, Y., Vantus, T., Sturany, S., Malhotra, V., Vandenheede, J. R. and Seufferlein, T. (2002). Protein kinase D: an intracellular traffic regulator on the move. Trends Cell Biol. 12, 193-200.

Verhey, K. J., Meyer, D., Deehan, R., Blenis, J., Schnapp, B. J., Rapoport, T. A. and Margolis, B. (2001). Cargo of kinesin identified as JIP scaffolding proteins and associated signaling molecules. J. Cell Biol. 152, 959-970.

Watson, F. L., Heerssen, H. M., Bhattacharyya, A., Klesse, L., Lin, M. Z. and Segal, R. A. (2001). Neurotrophins use the Erk5 pathway to mediate a retrograde survival response. Nat. Neurosci. 4, 981-988.

Wu, S. H., Arevalo, J. C., Sarti, F., Tessarollo, L., Gan, W. B. and Chao, M. V. (2009). Ankyrin Repeat-rich Membrane Spanning/Kidins220 protein regulates dendritic branching and spine stability in vivo. Dev. Neurobiol. 69, 547-557.

Wu, S. H., Arevalo, J. C., Neubrand, V. E., Zhang, H., Arancio, O. and Chao, M. V. (2010). The ankyrin repeat-rich membrane spanning (ARMS)/Kidins220 scaffold protein is regulated by activity-dependent calpain proteolysis and modulates synaptic plasticity. J. Biol. Chem. 285, 40472-40478. 